\title{
O IMAGINÁRIO DO ARQUIVO EM DIVERTIDA MENTE: O PAPEL DOS AGENTES DE MEMÓRIA NA CONSTRUÇÃO DO SER INFORMACIONAL
}

THE ARCHIVE IMAGINARY IN INSIDE OUT: THE ROLE OF THE MEMORY AGENTS IN THE CONSTRUCTION OF THE INFORMATIONAL BEING

${ }^{1}$ Thayron Rodrigues Rangel

${ }^{2}$ André Januário da Silva

${ }^{1}$ Arquivo Nacional

${ }^{2}$ Conselho Regional de Química $3^{\text {a }}$ Região

\section{Correspondência}

Thayron Rodrigues Rangel

Arquivo Nacional

Rio de Janeiro, RJ - Brasil

E-mail: thayron.rangel@gmail.com

Submetido em: 17/05/2018

Aceito em: 13/11/2018

Publicado em: 07/12/2018

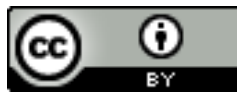

JITA: DL. Archives. 


\section{RDBCI

\section{RESUMO}

Objetiva discutir o contexto das instituições arquivísticas e o papel dos profissionais de arquivo na atualidade. Demonstrar como o paradigma da informação tem redimensionado não apenas as atividades dos arquivistas, mas também os usos e usuários do documento arquivístico. Para tanto, buscamos traçar um paralelo com o filme Divertida Mente (2015) que conta a história de Riley, uma menina de 11 anos, que vive em conflito, consigo e com seus pais, após se mudar de sua cidade natal. O filme é protagonizado pelas emoções, Alegria, Tristeza, Medo, Nojinho e Raiva, responsáveis por conferir à menina suas características de comportamento e também pelo armazenamento e tratamento de suas memórias. Nesse sentido, é possível apreender através do filme a ideia da mente como uma instituição arquivística, e das emoções como profissionais de arquivo responsáveis pela acumulação, seleção, armazenamento e descarte das memórias da personagem. Temos nessa realidade imaginada através do filme, as memórias de Riley como documentos arquivísticos fundamentais na constituição da identidade da personagem e na sua interação com os grupos sociais dos quais faz parte. Assim, podemos dizer que as instituições arquivísticas são ambientes orgânicos, em transformação e fortemente marcados pela atuação dos arquivistas, vistos como agentes de memória fundamentais na formação das identidades. Essa representação vai de encontro a algumas das principais características cristalizadas na área, como a naturalidade dos documentos e a imparcialidade dos profissionais de arquivo. Por fim, também redimensiona o documento arquivístico que passa a ter seu horizonte traçado pela noção de informação.

\section{PALAVRAS-CHAVE}

Arquivista. Documento Arquivístico. Memória.

\section{ABSTRACT}

This paper aims to discuss the archival institutions context and the role of archival professionals in the present day. Demonstrate how information paradigm has scaled the archivists activities, and the uses and users of the archival document. To do so, we did a parallel to the film Inside Out (2015), a movie about Riley, an 11-yearold girl who lives in conflict with herself and her parents after moving from her hometown. The film stars five emotions: Joy, Sorrow, Fear, Disgust, and Anger, which inhabit Riley's mind and it goes almost entirely in the character's mind. In the film, emotions are responsible for giving the girl her behavioral characteristics and also for the storage and treatment of her memories. In this context, it is possible to perceive through the film the idea of the mind as an archival institution, and of the emotions as archival professionals responsible for accumulating, selecting, storing and discarding the character's memories. We have in this reality imagined through the film, Riley's memories as archival documents of great importance in the constitution of the character's identity and in her interaction with the social groups she is part of. Thus, we can say that archival institutions are organic environments, in transformation and strongly marked by the work of archivists, seen as agents of fundamental memory in the formation of identities. This representation goes against some of the main characteristics consolidated in the area, such as the naturalness of documents and the impartiality of archival professionals. Finally, it also redefines the archival document object, which is now understood from the point of view of information.

\section{KEYWORDS}

Archivist. Records. Memory. 


\section{RPBO $\begin{aligned} & \text { Revista Digital Biblioteconomia e Ciência da } \\ & \text { Informação }\end{aligned}$ P B B

\section{Introdução}

Na contemporaneidade os Arquivos têm ganhado relevância muito em parte, devido ao dispositivo informacional que deles pode se extrair. Com o advento da Sociedade da Informação (MATTELART, 2002) ocorre um redimensionamento da cosmovisão e habitus na natureza social das profissões e da sociedade em geral. Assim, a informação toma centralidade não somente nas ações de indivíduos, mas também na ação do Estado, das grandes corporações e das técnicas que envolvem o universo do trabalho e o mundo social, tornando-se motor da lógica globalizante (SANTOS, 2006).

Nesse cenário, as instituições arquivísticas surgidas pós-revolução francesa, com a missão de preservar e salvaguardar o patrimônio e a memória nacional, se reconfiguram redimensionando seu espectro sob o paradigma do desenvolvimento tecnológico e da era informacional (FONSECA, 2013). Outrora, objeto protagonista da área, o documento arquivístico, passa a dividir espaço com a noção de Informação Arquivística, possibilitando assim, novas conjecturas não só para o campo científico, mas também para a práxis do profissional de arquivo e para os usos dos documentos.

Segundo Fonseca (2013), esse novo contexto aponta para a possibilidade de um novo perfil de profissional de Arquivo, que atua para além da dimensão técnica, compreendendo a relevância da sua atividade como um elemento salutar, para a transformação social. Outrossim, ocorrem discussões acaloradas acerca da instituição Arquivo e seu objeto de estudo. Como nos diz Cook (2012), ocorre a necessidade de reestruturação da abordagem do campo arquivístico, visto que as antigas estratégias e metodologias, alicerçadas nos estudos tipológicos e diplomáticos, já não são viáveis num mundo pós-moderno e computadorizado (COOK, 2012).

Ocasionando uma mudança paradigmática, o pós-modernismo trouxe à tona, uma discussão anacrônica ao papel das instituições arquivística e dos agentes profissionais, surgida ainda no século XIX. Alicerçada sobre a teoria Positivista, vimos a necessidade de reestruturação da abordagem do campo arquivístico, visto que as antigas estratégias e metodologias, alicerçadas nos estudos tipológicos e diplomáticos, já não são viáveis num mundo pós-moderno e computadorizado (COOK, 2012).

No caso brasileiro esse anacronismo é latente uma vez que a realidade das instituições arquivísticas, seja no âmbito público ou privado, ainda é fortemente marcada por um caráter prescritivo e custodial. Mesmo os elementos que remetem às práticas da Gestão de Documentos no Brasil, como a lei 8.159/91 e a Resolução 14/2001 do Conselho Nacional de Arquivos, são pouco viabilizados em razão de diversos fatores de ordem política e sociocultural (INDOLFO, 2013). 


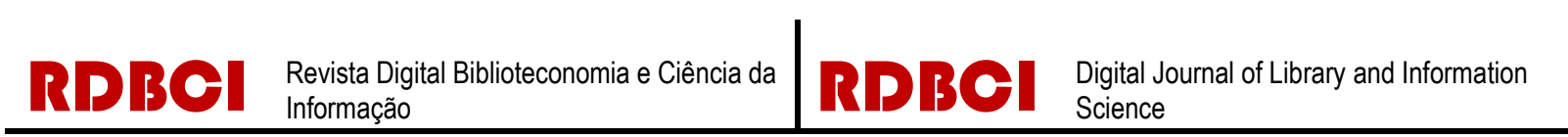

Assim, temos a animação Divertida Mente (2015), produzida pelos estúdios Pixar e Walt Disney, onde objetivamos discutir a relação entre a instituição Arquivo e os arquivistas, como agentes de transformação social na contemporaneidade. Para tanto, destacamos dois elementos de suma importância na compreensão dessa analogia: os conceitos de Informação Arquivística e Memória Social.

O filme Divertida Mente retrata as experiências vividas por Riley, uma menina de 11 anos que acaba de se mudar com seus pais, de sua cidade natal Minnesota, para a cidade de São Francisco. O filme é narrado e protagonizado pelas emoções de Riley: Alegria, Tristeza, Medo, Nojinho e Raiva. No filme, as emoções são responsáveis por construir a identidade da personagem a partir das memórias que são produzidas, selecionadas e registradas em esferas que determinam os fatores característicos da sua personalidade e convívio social.

Nessa narrativa, as memórias da menina são apresentadas como documentos arquivísticos, imprescindíveis para a construção do seu processo identitário. Assim, tal qual um documento arquivístico, estas memórias são submetidas aos fluxos e práticas inerentes ao fazer profissional desse campo. É importante destacar que nesse processo de produção, acumulação e destinação das esferas de memória, a mente de Riley é imaginada tal qual um grande Arquivo vivo em transformação.

Perpassando por toda a cadeia de custódia desde a produção a disponibilização para acesso e a eliminação, é possível identificarmos ao longo do filme, as funções arquivísticas e as demais atividades integrantes desta práxis, onde se destaca o protagonismo das emoções de Riley como agentes de memória.

\section{Contexto do Arquivo da Gênese a Atualidade}

Para que possamos abordar os elementos Informação Arquivística, Memória Social e Arquivologia é preciso que façamos uma breve digressão em torno do percurso histórico do campo arquivístico através dos tempos. Como sabemos, a disciplina arquivística enquanto prática, é algo que remonta os primórdios da humanidade. É possível mapear suas práticas desde a era pré-clássica, passando pela Antiguidade Clássica, período medieval, Renascimento, até o período pós-Revolução Francesa, onde algumas de suas conceituações técnicas basilares foram adotadas, tais como: o princípio da proveniência e respeito aos fundos (MARQUES, 2011).

Em "A trajetória da Arquivologia", Silva (2011) apresenta três perspectivas que identificam a trajetória do campo: a histórica, a gerencial e a informacional. A primeira dimensão aborda a Arquivologia com uma instituição meramente custodiadora dos 


\section{RDBCI

documentos produzidos, uma abordagem ainda, muito focada no agente profissional como um guardião de memória.

Uma revolução no pensamento sobre o material arquivístico aconteceu no século 19 com o surgimento de arquivos históricos como instituições. O trabalho de classificação e organização desses arquivos, de acordo com sua pertinência cedeu lugar, nas instituições europeias, ao respeito pelas origens dos conjuntos documentais e pela estrutura conferida a eles pelas entidades que os produziram. Ao final daquele século, arquivistas com sólida formação em história, idiomas antigos, paleografia e diplomática tornaram-se necessários para lerem e compreenderem documentos [...] (EASTWOOD, 2016, p. 21).

Ainda segundo Silva (2011), entre as décadas de 1930 e 1950, surge a visão gerencial. Esta que tem por base o caso norte-americano e sua relação com a gestão documental, mais precisamente o caso Hoover no contexto do pós-guerra, estabeleceu a organização governamental, tendo como base a racionalização dos processos e fluxos a partir da gestão dos documentos.

Esse contexto ocorre diante do desenvolvimento das Tecnologias de Informação e Comunicação (TIC), onde o fluxo e a produção de documentos atingem um aumento exponencial e acelerado no pós-guerra. É ainda na visão gerencial, que surge a Teoria das Três Idades: corrente, intermediária e permanente, delimitando toda a cadeia temporal de custódia de documentos arquivísticos. É definida como a "[...] sucessão de fases por que passam os documentos (corrente, intermediária, permanente), desde o momento em que são produzidos até sua destinação final (eliminação ou guarda permanente)" (BRASIL, 2004).

Nesse universo, fica claro que as práticas arquivísticas tomam o documento como principal objeto de suas conceituações. No Brasil, mais precisamente da Era Vargas em diante, temos o surgimento da Fundação Getúlio Vargas (FGV) e do Departamento Administrativo do Serviço Público (DASP), dois organismos com fins relacionados ao gerenciamento administrativo dos documentos. Assim, o documento é o objeto central nas políticas governamentais relacionadas aos arquivos. Vemos, portanto, que a Arquivologia se encontra historicamente marcada pelas práticas que visam à guarda e à preservação dos documentos, estando fortemente ligada ao contexto custodial.

É na década de 1980, que surgem as primeiras expressões relacionadas ao conceito de informação arquivística na literatura da área. Nesse sentido, essa nova abordagem dimensiona o arquivo na dinâmica informacional que marca a contemporaneidade, assim definimos a terceira dimensão, apresentada por Silva (2009), que versa sobre a trajetória da arquivologia. Para Jardim $(2010 ; 2012)$ a noção de informação arquivística, tem estreito relacionamento com a aplicação do conceito de Gestão de Documentos que surge no Brasil na década de 


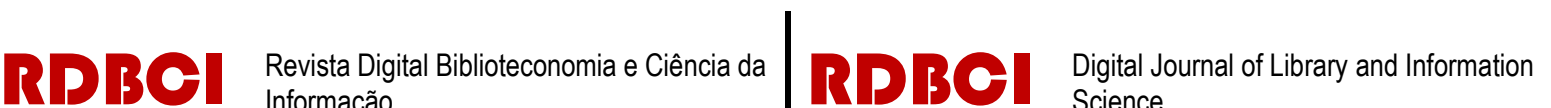

1980 e fornece elementos que fazem aflorar as primeiras discussões teóricas acerca do conceito na década de 1990.

Assim, é possível apreender que a noção de informação arquivística está associada a busca por um domínio mais amplo e, menos mecanicista e prescritivo da função em que atuava o profissional arquivista. Se outrora o trabalho era entendido fundamentalmente como estando assentado sobre o processamento técnico de documentos que resultam da atividade de uma pessoa física ou jurídica, agora sob a égide da informação, essa atuação é entendida para além dessa função, inserindo o profissional de arquivo no funcionamento da organização do conhecimento (SILVA, 2009), assumindo assim, o papel de mediador e analista da informação.

É nesse contexto que a memória sob o ponto de vista social na atividade arquivística, transcende seu aspecto tradicional de objeto oficial a ser monumentalizado, para alcançar um status que remete aos processos de construção social, muitas vezes com potencial de ação em relação a grupos, indivíduos e estratos sociais a margem da memória oficial da nação (JARDIM, 1995). Para Panisset e Assis (2016, p. 84),

os arquivos representam a atividade humana e social, são um reflexo de atividades que caracterizam momentos históricos, grupos sociais, atividades econômicas e uma infinidade de outros aspectos da sociedade. Isso acontece porque os documentos que os compõem vão além do caráter de prova, pois eles também são o aparato para o reforço e a constituição da memória social.

É a partir desse redimensionamento do papel do Arquivo como um possibilitador de transformação social, que temos no profissional de arquivo uma nova realidade atuante. Enquanto agentes ativos de memória possuem participação fundamental nas garantias de direitos do cidadão ao acesso à informação, no desenvolvimento de ações afirmativas, na produção de novas identidades e memória coletiva.

\section{Imaginário do Arquivo em "Divertida Mente"}

Compreendendo os Arquivos como instituições integrantes do processo de construção da memória coletiva, temos na animação Divertida Mente, um exemplo da rotina arquivística e do papel atual do arquivista no processo de desenvolvimento da identidade de grupos sociais. Hoje, vemos um diálogo crescente nos estudos de Memória Social em relação ao campo da Arquivologia, sendo abordados pelas temáticas ligadas ao desenvolvimento social, políticas afirmativas, da memória como fonte de informação e conhecimento e do impacto das TIC, no universo social contemporâneo. Outrossim, em relação ao papel social do arquivista no processo de construção da memória coletiva de grupos sociais e em novas abordagens de identidade social (JARDIM, 1995) (SILVA, 2009). 


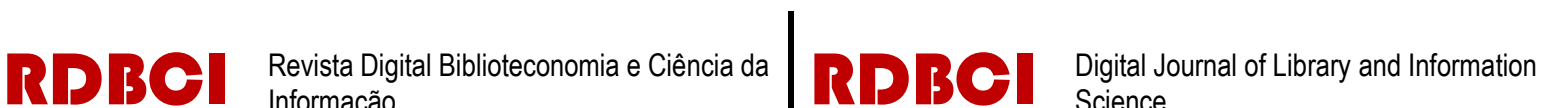

Lançado em 2015, Divertida Mente (Inside Out) foi um enorme sucesso de público e crítica tornando-se uma das maiores bilheterias daquele ano, dentre outras láureas foi indicado a dois Oscars, vencendo o prêmio de melhor animação no Oscar e Globo de Ouro (IMDB, 2017). O filme conta a história de Riley, uma menina de 11 anos natural de Minnesota que está de mudança com sua família para a cidade de São Francisco.

A princípio a personagem se mostra ansiosa para essa nova vida com seus pais, mas aos poucos vai se decepcionando com o lugar, muito em parte devido às suas lembranças e referências estarem cristalizadas a sua cidade natal, sua melhor amiga, sua escola e seu principal hobby o hóquei, modalidade esportiva, que recebeu como herança de seu pai. A partir da relação entre memória e informação e sua correlação com o campo da Arquivologia, analisaremos o filme destacando a metáfora da memória da personagem como um documento arquivístico pertencente a uma cadeia de custódia que envolve a mente de Riley como o centro de um grande arquivo responsável pela seleção, eliminação e guarda das memórias da menina.

Assim, também destacamos o importante papel das emoções como agentes sociais de memória, entendendo que a estas personagens cabe o papel de arquivistas, protagonistas na construção do processo identitário de Riley. Nesse sentido, trazemos a compreensão de Nora (1993) onde temos as instituições arquivísticas como lugares de memória, responsáveis pela preservação e acesso de informações e provas de ação de um passado, bem como, pela representação da atividade humana e social, refletindo assim momentos históricos.

\begin{abstract}
Os lugares de memória pertencem a dois domínios, que a tornam interessante, mas também complexa: simples e ambíguos, naturais e artificiais, imediatamente oferecidos a mais sensível experiência e, ao mesmo tempo, sobressaindo da mais abstrata elaboração. São lugares, com efeito nos três sentidos da palavra, material, simbólico e funcional, simultaneamente, somente em graus diversos. Mesmo um lugar de aparência puramente material, como um depósito de arquivos, só é lugar de memória se a imaginação o investe de uma aura simbólica (NORA, 1993, p. 21).
\end{abstract}

Narrado inicialmente pela Alegria, o filme inicia a história, demonstrando a importância e o papel das emoções na vida da menina. Para tornar compreensível nossa analogia entre as emoções da personagem e o papel que elas desempenham como agentes de memória em sua mente é preciso destacar a forma como elas são apresentados na narrativa fílmica.

Em princípio a mente de Riley é escura e a primeira emoção retratada é a Alegria, que surge concomitantemente ao nascimento da menina, quando esta ainda é um bebê. Alegria, é um personagem feminino, possui uma aura radiante, tem a pele clara e cabelos e olhos azuis. É esbelta, traja um vestido amarelo brilhoso e sua principal característica é o otimismo, típico desse sentimento. A segunda emoção apresentada é a Tristeza. Essa personagem contrasta

\begin{tabular}{l} 
(c) RDBCl: Rev. Digit. Bibliotecon. Cienc. Inf. \\
\hline
\end{tabular}




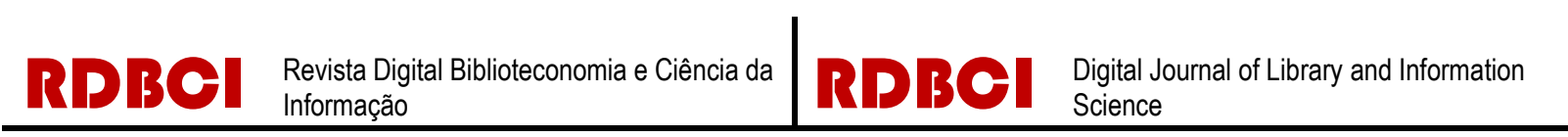

totalmente com a Alegria. De cor azul clara, essa personagem também feminina tem baixa estatura, forma rotunda, possui óculos e um casaco branco. Com semblante triste, uma de suas principais características é o pessimismo. Essa personagem surge quando Riley ainda bebê tem o primeiro acesso de tristeza que lhe leva às lágrimas.

O Medo é a terceira emoção apresentada, surge quando ainda muito criança, Riley começa a desbravar o espaço de sua casa. O Medo é um personagem masculino, possui estatura mediana, tem a pele roxa, olhos esbugalhados e veste um suéter xadrez nas cores preta e branca, gravata borboleta na cor vinho e representa o senso de segurança e prudência da menina, quando ela está em situações de risco.

A quarta emoção apresentada é Nojinho e surge quando ainda na primeira infância, Riley vai ingerir brócolis pela primeira vez. Esta personagem é representada pelo gênero feminino, possui baixa estatura, pele verde, olhos e cílios grandes, e usa um vestido verde com estampas florais amarrado por um cinto também verde, na altura da cintura. Traz consigo um lenço lilás amarrado em seu pescoço, cabelos lisos na altura dos ombros e batom vermelho, apresentando fortes traços de feminilidade. Como nos diz Alegria, esta emoção é responsável por evitar que Riley se envenene física e socialmente.

A quinta e última emoção apresentada é o Raiva. Surge quando após se recusar a comer brócolis, o pai de Riley a ameaça ficar sem sobremesa. O Raiva é um personagem masculino, de baixa estatura, cor de pele vermelha e que expele fogo pela cabeça, de formato quadrado. Sua indumentária nos remete a figura de um executivo, com camisa social, calça cargo marrom, cinto e sapatos pretos e gravata listrada nas cores branca e vermelha. Para Alegria esta emoção representa o ímpeto de revolta de Riley em relação ao que considera ser injustiças cometidas contra ela.

Agentes componentes da estrutura mental da menina, essas cinco emoções alicerçam toda a ação e narrativa fílmica, que se passa em grande parte da Sala de Comando para outros compartimentos e espaços arquivísticos que compõem a sua mente. Integram esta sala, uma mesa de controle responsável por acionar as atividades das emoções junto a personalidade de Riley, por canais internos que recebem as memórias em esferas. Nessa perspectiva, a cada ação impetrada por cada uma das emoções, ocorre a cristalização de um sentimento em uma esfera que armazena determinada memória e ficam armazenadas, ainda na Sala de Comando, em uma estante, que potencializa a representação de um arquivo corrente.

Inicialmente as esferas são apresentadas de forma unicolor, onde cada cor representa uma emoção. Assim, a esfera amarela simboliza as ações provocadas pela Alegria, as azuis as da Tristeza, as de cor lilás as esferas do Medo, as verdes as da Nojinho e a vermelhas do personagem Raiva. Ao término de cada dia, quando Riley adormece as esferas produzidas ao \begin{tabular}{l|l|l|l|l|l}
\hline ๑ RDBCl: Rev. Digit. Bibliotecon. Cienc. Inf. & Campinas, SP & v.17 & $1-16$ & e019008 & 2019
\end{tabular} 


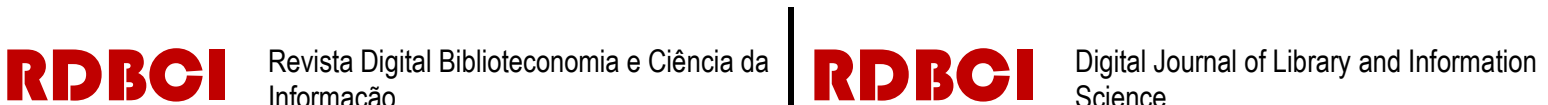

longo do dia, são enviadas por um canal central aos Arquivos de Longo Prazo localizados num ambiente exterior a Sala de Comando. Também compõem esse espaço, a Biblioteca de Manuais e Procedimentos referentes a todo processo de geração, armazenagem, eliminação e ainda de gestão das memórias recentes, de longo prazo e ainda das Memórias Base, que não podem ser descartadas ou retiradas de seu local de guarda, tidas por nós, como documentos permanentes.

Compreendemos assim a mente da menina Riley, como uma Unidade de Informação Arquivística, em virtude das similitudes entre o espaço e as rotinas representados na animação com o campo teórico profissional da Arquivologia. Partindo desse pressuposto, podemos perceber de forma clara, a relação direta do filme com a teoria do campo da Arquivologia. Afinal, para Cook e Schwartz (2002, p.16)

os arquivos - como registros - exercem poder sobre a construção do conhecimento histórico, da memória coletiva e da identidade nacional, sobre como nós nos conhecemos como indivíduos, grupos e sociedades. E por fim, na busca de suas responsabilidades profissionais, os arquivistas - como gestores de arquivos - detêm o poder sobre os próprios documentos essenciais à formação da memória e da identidade.

Outro importante elemento representativo no filme é a construção da ideia de que as esferas de memórias são tratadas pelas emoções como documentos arquivísticos, uma vez que como dito anteriormente, possuem tratamento e funcionalidade característicos dos documentos de natureza arquivística. Desta forma trazemos a contribuição de Buckland (1991, p.7) que nos diz que

[...] considerar qualquer coisa tão informativa quanto o "documento" é consistir com as origens e o uso da palavra, que deriva do verbo Latim docere, para aprender ou para informar, com o sufixo "-ment" denotando significado. Conseqüentemente "documento" originalmente denota um significado de aprendizagem ou informação, assim como uma lição, uma experiência, ou um texto.

Entretanto, quando tratamos o documento arquivístico comparado as demais ciências que também possuem o documento como objeto científico, encontramos algumas peculiaridades relacionadas a natureza de sua gênese, ante os demais. Assim, entende-se que a informação e, por conseguinte, o documento arquivístico, são aqueles produzidos, recebidos e acumulados por um organismo, em razão das competências e atividades necessárias para a realização de seus objetivos (SILVA, 2008). Em razão da natureza multifacetada desse documento, temos numa visão mais ampla do conceito de documento, a abordagem apresentada por Rondinelli (2013, p. 46 apud HEREDIA HERRERRA, 1991, P.121). 


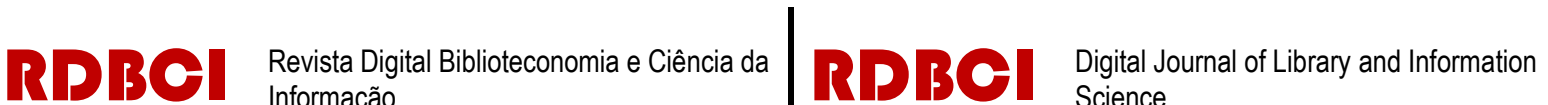

\begin{abstract}
Documento em um sentido muito amplo e genérico é todo registro de informação independentemente de seu suporte físico. Abarca tudo o que pode transmitir o conhecimento humano: livros, revistas, fotografias, filmes, microfilmes [...], mapas [...], fitas gravadas, discos, partituras [...], selos, medalhas, quadros [...] e de maneira geral tudo o que tenha um caráter representativo nas três dimensões e que esteja submetido à intervenção de uma inteligência ordenadora.
\end{abstract}

Para ,Schellenberg(1956, p.13 apud RONDINELLI, 2013, p. 157). os documentos arquivísticos podem ser compostos por várias formas e origens. Mas para desfrutarem das características que compõem a natureza arquivísticas precisam, “[...] ser produzidos no curso de uma atividade intencional e organizada [...]" e devem ser criados "[...] durante um processo de cumprimento de algum negócio administrativo, legal, ou outro objetivo social $[\ldots] "$.

No que tange as Memórias Base, citadas anteriormente, como alicerces do processo identitário de Riley, temos a partir do devido arquivamento destas, a construção das chamadas Ilhas de Personalidade. Estas ilhas, estão ligadas a Sala de Comando por meio de canais e são alimentadas pelas Memórias Base - documentos permanentes, nutrientes responsáveis por sua criação. Constituem as Memórias Base cinco documentos permanentes, ou seja, esferas de memória armazenadas no centro da sala. Assim, as ilhas, se constituem como base das principais referências que constituem a identidade de Riley, em relação aos grupos sociais que pertence e em relação ao seu processo de interação neles. Sendo assim, temos as seguintes ilhas: Amizade, Honestidade, Família, Bobeira e Hóquei.

Como dito anteriormente, ao término de cada dia, as memórias (correntes) são recolhidas para o chamado Arquivo de Longo Prazo, onde os sistemas de ordenação e localização, são apresentados a partir da separação por competências - Ilhas - e arquivadas em ordem cronológica.

Durante o processo de consulta e pesquisa a emoção Tristeza, toca em uma das esferas de memória (documentos) e altera em definitivo o valor e o significado que este possuía até então. Durante este plano a Alegria comenta com a Tristeza que se as memórias mudarem elas não saberiam como "consertar". Até então, percebemos que os documentos estavam ligados diretamente a uma única competência e atividade de Riley. Notamos uma dicotomia apresentada a partir dessas personagens, onde acredita-se que o trabalho desenvolvido pela Alegria, possui maior significância para com o desenvolvimento dos símbolos que contribuem com a formação identitária da personagem. Esse fato nos leva ao nosso próximo tópico onde pretendemos discutir o papel dos agentes de memória na condição de arquivistas. 


\section{RPBO $\begin{aligned} & \text { Revista Digital Biblioteconomia e Ciência da } \\ & \text { Informação }\end{aligned}$ P B B

\section{Os Agentes de Memória e seu Papel na Construção das Identidades}

Atordoada com o fato da esfera de memória de cor amarela, a qual simboliza a Alegria, ter sido alterada para a cor azul, quando tocada pela emoção Tristeza, a personagem Alegria demonstra uma preocupação comum e pertinente ao fazer arquivístico; a irreversão das alterações documentais. A priori, temos da impressão da irreversibilidade que essa alteração de cor e de emoção da esfera, trazida do arquivo de longo prazo para consulta imediata, pelas tubulações que representam os fluxos documentais.

Percebemos aqui, o importante papel do agente social analisado (o Arquivista). Para Eastwood (1997, p.27-38 apud DUFF, 2016, p.172) o principal papel do Arquivista "é proteger a integridade dos documentos, ou seja, disponibilizá-los deve vir depois que as tarefas primordiais forem executadas". Assim, sem a intenção de causar mais danos, a Tristeza se aproxima do local de guarda das esferas de Memória Base, até então todas amarelas, que começam a azular, até que Alegria a interrompe e sinaliza que caso alterem a cor, elas não saberão como consertar. E novamente, Tristeza se aproxima do local de guarda dessas memórias permanentes, alegando que irá reorganizá-las. Alegria tenta evitar que Tristeza entre em contato com as memórias base, estas acabam caindo no chão. Ao recolher as esferas, uma delas acaba sendo sugada pela tubulação que leva as esferas de memória diária, para o espaço fora da Sala de Comando. Assim, na tentativa de impedir a sucção, por descuido, das Memórias Base ao outro ambiente de guarda, a Alegria acaba sendo sugada juntamente as esferas e, ao tentar auxiliá-la a Tristeza acaba por ir junto.

Após percorrer a parte da tubulação que devolve as esferas ao Arquivo de Longo Prazo, as personagens, iniciam a odisseia de descobrimento dos fluxos, processos e ainda, de todo o universo que existe além da sala. Percebemos assim, que os Agentes de Memória - as Emoções, são responsáveis apenas pelo gerenciamento das esferas. A trajetória das duas personagens além da Sala de Comando, permite uma amplitude na percepção de toda complexidade envolvida na guarda, manutenção, seleção e descarte dessas memórias.

Acumuladas de forma cronológica, atendendo assim de forma sumária, ao princípio da ordem original, as esferas de memória, independe de suas cores, são armazenadas em grandes estantes onduladas, localizadas posteriormente as cinco Ilhas de Personalidade, onde cada conjunto de estantes, encontram-se posicionadas atrás de cada ilha.

Paralelamente a esse fato, na Sala de Comando as outras três Emoções, Medo, Nojinho e Raiva, assumem o controle da produção de personalidade de Riley. Entretanto, sem as duas Emoções faltantes é perceptível o descontrole para exercer as atividades, visto que esse é um trabalho que depende da presença e atuação das cinco Emoções. Outro importante fator a ressaltar é que uma vez, que as Memórias Base são retiradas do seu local de armazenamento,

\begin{tabular}{l|l|l|l|l|l}
\hline (c) RDBCl: Rev. Digit. Bibliotecon. Cienc. Inf. & Campinas, SP & v.17 & $1-16$ & e019008 & 2019 \\
\hline
\end{tabular}




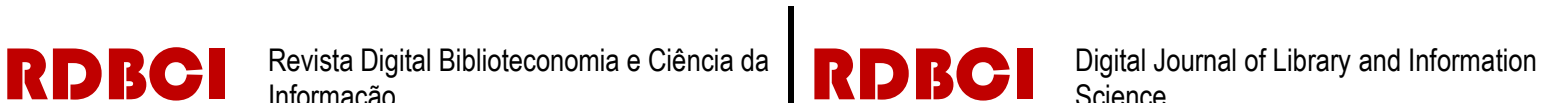

as Ilhas de Personalidade, começam aos poucos a se desintegrar, já que essas esferas de memória são as bases de sua sustentação.

Simultaneamente a esse acontecimento, no mundo externo Riley começa a apresentar apatia e indiferença às coisas que a circundam, devido à ausência das Memórias Base (documentos permanentes) e das personagens Alegria e Tristeza. Havendo apenas a possibilidade de externalizar raiva, nojo e medo, a menina assume uma identidade diferente da construída em conjunto pelas cinco emoções. Com isso, diante dos seus problemas diários, como a ausência dos seus amigos, a saudade de sua cidade natal e do seu time de hóquei e, do conflito com seus pais por conta da mudança, Riley resolve fugir de casa.

Após uma Odisséia pela mente de Riley, Tristeza e Alegria, auxiliadas por um amigo imaginário pertencente ao passado da garota, mas que estava esquecido nos arquivos de Longo Prazo, e também pelo conhecimento adquirido pela Tristeza após consulta aos Manuais e Procedimentos sobre o funcionamento, atividades e fluxos da mente de Riley, as duas emoções conseguem retornar a Sala de Comando.

Uma vez de volta, juntas as cinco emoções tentam reverter a fuga de Riley, o retorno ao seu lar e a reconciliação com seus pais. Após várias tentativas estimuladas principalmente pela Alegria, estes percebem que a Tristeza vista até então como uma presença negativa na mente da menina, será a emoção fundamental para reverter esse quadro. Ao assumir o comando da sala, a Tristeza desperta saudade das lembranças de Riley sobretudo, em relação ao seus pais. Este fato causa arrependimento na personagem que desiste de sua fuga, retorna ao seu lar e se reconcilia com eles.

Com isso, as emoções percebem que o trabalho em conjunto é fundamental para equilibrar a identidade de Riley, e que sem ele as atividades que desenvolvem não fazem sentido. Percebemos então, a responsabilidade dos profissionais de informação de "absorver, filtrar, organizar, analisar e disseminar essa informação de acordo com o cenário no qual está inserido" (OLIVEIRA, ALVES, MAIA, 2013, p. 7).

Nesse viés, elegemos como responsabilidades do arquivista o papel ativo na construção da memória social, na autorreflexão, na capacidade de recuperar o contexto de produção dos documentos arquivísticos. $\mathrm{O}$ trabalho do arquivista contribui ainda para sua autoidentificação como sujeito e agente da historicidade, como formador da memória e também promotor da visão do arquivo como resultado da experiência humana (PANISSET; ASSIS, 2016, p.8586).

Podemos assim dizer que as cinco emoções são um todo orgânico que compõem a mentalidade da garota. Logo, as memórias bases de cor única e moldadas apenas pela Alegria

\begin{tabular}{l|l|l|l|l|l|}
\hline (c) RDBCl: Rev. Digit. Bibliotecon. Cienc. Inf. & Campinas, SP & v.17 & $1-16$ & e019008 & 2019 \\
\hline
\end{tabular}




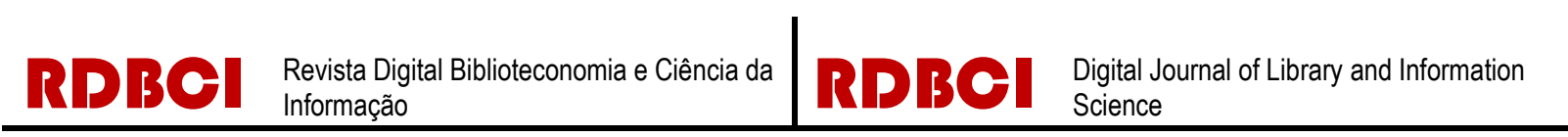

passam a ser multicoloridas contendo elementos das cinco emoções. Com isso, as ilhas de personalidade que representavam em grande parte da animação, uma única personalidade, após o retorno de Riley para casa, passam a ser abastecidas também pelas outras emoções dando um aspecto muito mais diverso a identidade da personagem, assim como as esferas de memória, que também passaram a serem produzidas a partir de duas ou mais emoções.

Esse aspecto é fundamental para a reconfiguração de algumas ilhas de personalidade como a da família, por exemplo, assim como são formadas novas ilhas de personalidade que dão lugar a outras que já não contextualizam a identidade atual da menina. A ilha da Bobeira, muito ligada a sua fase infantil dá lugar a ilha das boy band, interesse característico de sua fase atual de adolescente. Com isso notamos que o arquivo enquanto instituição é mutável e está em constante transformação, pois é resultado do contexto diário de quem o produz.

Para nós, toda essa cosmovisão apresentada em Divertida Mente encontra reflexos na realidade atual dos arquivos e dos seus profissionais sendo um universo em potencial a ser problematizado pelos pesquisadores da área. Por outro lado, embora como dito anteriormente a informação e seus produtos na realidade contemporânea tenham tomado centralidade na área arquivística, o campo ainda traz raízes muito fincadas em um modelo custodial e positivista.

Duranti (1994) aponta cinco características que alicerçam o documento arquivístico, sendo eles: imparcialidade; autenticidade; naturalidade; inter-relacionamento; unicidade. Todas essas características trazem consigo, uma forte marca de crença na neutralidade da produção e guarda dos documentos, assim como também demonstra forte preocupação em sedimentar os princípios arquivísticos dentro de uma esfera de oficialidade e historicismo. A nosso ver, essa afirmativa apresentada pela autora e compartilhada por outros cânones clássicos da área como Bellotto (2013), reflete um distanciamento entre o que é produzido, quem o produz e quem o armazena, desconsiderando os embates, as escolhas e as construções ideológicas próprias das relações sociais humanas. Nessa perspectiva, a entidade arquivo é vista como instituição a ser zelada e preservada e o arquivista como guardião de registros documentais.

\section{Considerações Finais}

Neste trabalho abordamos o conceito de memória, enquanto documento arquivístico e buscamos traçar um paralelo com o filme Divertida Mente (2015) que conta a história de Riley, uma menina de 11 anos, que vive em conflito, consigo e com seus pais, após se mudar de sua cidade natal. O filme é protagonizado pelas emoções Alegria, Tristeza, Medo, Nojinho e Raiva, que por nós são trazidos ao debate, como agentes sociais de memória. Nesse sentido,

\begin{tabular}{l|l|l|l|l|l|}
\hline (c) RDBCl: Rev. Digit. Bibliotecon. Cienc. Inf. & Campinas, SP & v.17 & $1-16$ & e019008 & 2019 \\
\hline
\end{tabular}




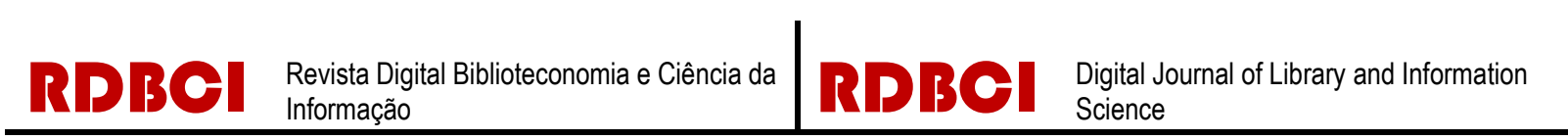

é possível apreender através do filme a ideia da mente, como uma instituição arquivística, e das emoções, como profissionais de arquivo responsáveis pela acumulação, seleção, armazenamento e descarte das memórias da personagem.

Essa representação vai de encontro a algumas das principais características cristalizadas na área, como a naturalidade dos documentos e a imparcialidade dos profissionais de arquivo. Vimos assim, a mudança do perfil restrito as competências custodiais para um profissional que possui papel de mediador e partícipe do processo de construção das identidade individuais e coletivas dos usuários de informação.

Esse trabalho nos possibilitou também, redimensionar o documento arquivístico que passou a ter seu horizonte traçado pela noção de informação. Desta forma, a animação nos demonstra esse importante papel dos agentes de memória, "[...] num processo estruturador dos seus espaços. Espaços científicos, tecnológicos, sociais. Espaços de crise e crescimento" (JARDIM, 1998, p.1).

Com base na análise realizada através do filme podemos apontar para outra realidade, que nos apresenta o Arquivo como um todo orgânico, contextual e de caráter cíclico, uma vez que o processo de produção do documento reflete a interação de quem o produz com quem o armazena. Assim, temos a memória como componente formador do documento não como um constructo cristalizado, mas como resultado do processo de interação entre indivíduos junto aos grupos sociais aos quais pertencem.

Nesse contexto, o papel dos agentes de memória (arquivistas) é reflexo de um trabalho coletivo com outros agentes sociais e se aplica de acordo com as necessidades e usos do usuário do documento, indo de encontro à visão de guardiões de uma memória social cristalizada. Os agentes de memória, assim como os documentos são produtos do meio, das experiências vividas, de embates e acordos, de ideologias e de verdades relativas, não cabendo mais apenas o papel tecnicista e imparcial. Assim como os documentos não são verdades absolutas sobre as coisas, a eles cabe relativizar seu contexto de produção, pois são passíveis de ressignificação e transformação, de acordo com a lógica dos indivíduos e dos grupos sociais.

\section{Referências}

BELLOTTO, Heloísa Liberalli. Arquivos permanentes: tratamento documental. Rio de Janeiro: FGV, 2013.

BRASIL. Ministério da Justiça. Arquivo Nacional. Dicionário brasileiro de terminologia arquivística. Rio de Janeiro, 2004a. Disponível em:

\begin{tabular}{l|l|l|l|l|l}
\hline (c) RDBCl: Rev. Digit. Bibliotecon. Cienc. Inf. & Campinas, SP & v.17 & $1-16$ & e019008 & 2019
\end{tabular}




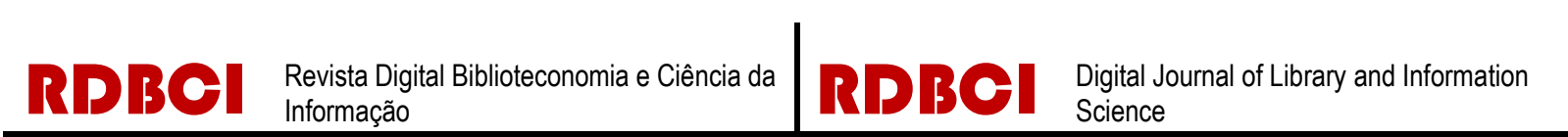

http://www.arquivonacional.gov.br/images/pdf/Dicion_Term_Arquiv.pdf. Acesso em: 12 jan. 2018.

BUCKLAND, Michael K. Information as thing. Journal of the American Society for Information Science (JASIS), v.45, n.5, p.351-360, 1991. Tradução livre de Luciane Artencio. Disponível em: http://www.uff.br/ppgci/editais/bucklandcomocoisa.pdf. Acesso em: 10 dez. 2017.

COOK, Terry; SCHWARTZ, Joan M. "Archives, Records, and Power: the making of modern memory”. In: Archival Science. v.2, n.1-2, p.1-19, 2002. Disponível em português em: http://www.promemoria.indaiatuba.sp.gov.br/arquivos/galerias/registro_3.pdf. Acesso em: 17 fev. 2018.

DIVERTIDA mente. Direção e co-autoria: Pete Docter. Co-direção: Ronnie Del Carmen. Produção: Jonas Rivera. EUA: Walt Disney Pictures Pixar Animation Studios, 2015.

DURANTI, Luciana. Registros documentais contemporâneos como provas de ação. Estudos Históricos, Rio de Janeiro, vol. 7, n. 13, 1994a, p. 49-64. Disponível em: http://bibliotecadigital.fgv.br/ojs/index.php/reh/issue/view/279. Acesso: 10 abr. 2018.

EASTWOOD, Terry. Publicado Services Educativo for Archivists. Reference Librarian, n.56, p.27-38. 1997.

FONSECA, Maria Odila. Arquivologia e Ciência da Informação. Rio de Janeiro: FGV, 2013.

HEREDIA HERRERA, Antonia. Archivística General. Teoría y Práctica. Sevilla. Diputación Provincial de Sevilla, 1991.

IMDB. Disponível em: 〈https://www.imdb.com/title/tt2096673/> (Internet Movie Data Base). Acesso em: 21 abr. 2018.

INDOLFO, Ana Celeste. Dimensões político-arquivísticas da avaliação de documentos na administração pública federal (2004-2012). Tese de Doutorado apresentada ao Programa de Pós-Graduação em Ciência da Informação, convênio entre o Instituto Brasileiro de Informação em Ciência e Tecnologia e a Universidade Federal do Rio de Janeiro/Escola de Comunicação. Rio de Janeiro: IBICT, 2013. Disponível em:

http://ridi.ibict.br/bitstream/123456789/893/1/Tese\%20Ana\%20Celeste.pdf. Acesso em 23 dez. 2017.

JARDIM, José Maria. Transparência e opacidade do Estado no Brasil: usos e desusos da informação governamental. Niterói, RJ: Eduff, 1999. 239 p.

JARDIM, José Maria. A pesquisa como fator institucionalizante da Arquivologia enquanto campo científico no Brasil. In: Anais da I reunião brasileira de ensino de Arquivologia. Brasília: Universidade de Brasília, 2010. V. 1. p.1-11.

\begin{tabular}{l|l|l|l|l|l}
\hline (c) RDBCl: Rev. Digit. Bibliotecon. Cienc. Inf. & Campinas, SP & v.17 & $1-16$ & e019008 & 2019
\end{tabular}




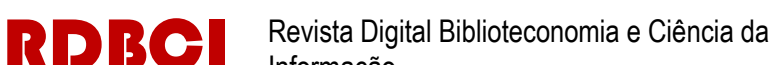 Informação

JARDIM, José Maria. A pesquisa em Arquivologia: um cenário em construção. In:

VALENTIM, Marta Lígia Pomim. Estudos avançados em Arquivologia. Marília: Oficina Universitária; São Paulo: Cultura Acadêmica, 2012. p. 135-154.

MARQUES, Angélica Alves da Cunha. Interlocuções entre a Arquivologia nacional e a internacional no delineamento da disciplina no Brasil. Brasília, 2011. Tese (Doutorado em Ciência da Informação). Programa de Pós-Graduação m Ciência da Informação/UnB.

MATTELART, Armand. História da sociedade da informação. São Paulo: Edições Loyola, 2002.

NORA, Pierre. "Entre memória e história: a problemática dos lugares". Tradução de Yara Aun Khoury. In: Revista do Programa de Estudos Pós-graduados em História do Departamento de História da PUC-SP. São Paulo, n.10, p. 7-28, dez. 1993.

OLIVEIRA, Magali Araújo Damasceno de; ALVES, Márcia Valéria; MAIA, Maria Aniolly Queiroz. A função social do profissional da informação numa biblioteca inclusiva. In: Anais do Congresso Brasileiro de Biblioteconomia, Documentação e Ciência da Informação, v. 5, 2013. Disponível em: https://www.portal.febab.org.br/anais/article/view/1600. Acesso em: 08 mar. 2018.

PANISSET, Bianca Therezinha Carvalho. ASSIS, João Marcus Figueiredo. A atuação do arquivista entre o dever de memória e o desejo de Arquivo. Revista do Arquivo Geral da Cidade do Rio de Janeiro, n.10, 2016, p.81-89. Disponível em: http://wpro.rio.rj.gov.br/revistaagcrj/wp-content/uploads/2016/11/e10_a04.pdf . Acesso em 19 abr. 2018.

RONDINELLI, Rosely Curi. O documento arquivístico ante a realidade digital: uma revisão necessária. Rio de Janeiro: FGV, 2013.

SANTOS, Milton. A natureza do espaço: Técnica e tempo. Razão e emoção. São Paulo: Editora da Universidade de São Paulo, 2006.

SILVA, Eliezer Pires. A noção de informação arquivística na produção de conhecimento em arquivologia no Brasil (1996-2006). Niterói, 2009. Dissertação (Mestrado em Ciência da Informação). Programa de Pós-Graduação em Ciência da Informação da Universidade Federal Fluminense/ Instituto Brasileiro em Informação Científica e Tecnológica.

SILVA, Sérgio Conde de Albite. A Preservação da Informação Arquivística Governamental nas Políticas Públicas do Brasil. Rio de Janeiro: AAB/FAPERJ, 2008.

THOMASSEN, Theo. The Development of Archival Science and its European Dimension. Seminar for Anna Christina Ulfsparre. 